\title{
DANO PSÍQUICO
}

\author{
Celeste Leite Dos SANTOS \\ Doutora pela USP \\ Especialista em Direito Penal Econômico \\ pela Universidade de Coimbra \\ Especialista em Interesses \\ Difusos e Coletivos pela CEAF-ESMP \\ Promotora de Justiça, Coordenadora Geral \\ dos Grupos de Estudos dos Membros do MPSP \\ celestesantos454@botmail.com
}

\section{RESUMEN}

O presente trabalho visa delimitar os danos psíquicos passíveis de responsabilização cível e criminal. É analisada a forma como os tipos de violência intrapessoal, interpessoal ou coletiva interferem na caracterização dos danos psíquicos. A seguir faz-se breve análise da violência contra mulheres, idosos e crianças e são apresentadas as conclusões ao trabalho.

Palabras clave: dano síquico, violência, trauma, estigmatização, vitimização, sobrevivente.

\section{ABSTRACT}

The aim of the present study is to delimitate passive psychical dammages subject to criminal and civil liability, analyzing the types of intrapersonal, interpersonal and colective violence of psychical dammages. Then, it is made a short summary regarding violence against women, the elderly and children and, finally, a list of main conclusions of the work are drawn.

Keywords: psychical dammage, violence, trauma, stigmatization, victimization, survivor.

\section{SCHLÜSSELWÖRTER}

Die vorliegende Arbeit versucht abzugrenzen, welche passiven psychischen Beschädigungen der zivil- und welche der strafrechtlichen Haftung unterliegen.

Es werden die Arten von intrapersönlicher, zwischenmenschlicher und kollektiver Gewalt untersucht, die charakteristisch für psychische Schädigungen sind. Anschließend wird eine kurze Untersuchung der Gewalt gegen Frauen, ältere Menschen und Kinder durchgeführt und die Untersuchungsergebnisse der Arbeit vorgestellt.

Zusammenfassung: psychische schädigungen, gewalt, trauma, stigmatisierung, viktimisierung, überlebender. 
SUMARIO: I. INTRODUÇÃO.-II. SAÚDE PÚBLICA E VIOLÊNCIA PSÍQUICA.-III. CARACTERIZAÇÃO DO DANO PSÍQUICO.-IV. DANO PSÍQUICO E VIOLÊNCIA CONTRA MULHERES.-V. DANO PSÍQUICO E VIOLÊNCIA CONTRA IDOSOS.-VI. DANO PSÍQUICO E VIOLÊNCIA CONTRA CRIANÇAS.-VII. CONCLUSÃO.-VIII. BIBLIOGRAFÍA.

\section{INTRODUÇÃO}

De acordo com a Organização Mundial da Saúde o conceito de saúde deve ser analisada em sua dimensão física, psíquica e social, sendo mais amplo do que a simples ausência de doença.

Antônio Carlos Lopes, Carolina Alves de Souza Lima e Luciano de Freitas Santoro, prelecionam que a proteção que é dada pela Constituição em relação ao direito à vida, vai além da biológica, abrange uma vida digna, que pressupõe a garantia dos direitos fundamentais, e abrange tanto os direitos básicos de sobrevivência como os vinculados ao bem estar psíquico e social e a legislação infraconstitucional vem para regulamentar e garantir a efetividade esse direito. Dessa forma, o direito à vida digna, abrange desde ao direito da sua inviolabilidade, até a garantia de que se tenha respeito, educação de qualidade, moradia, emprego, lazer, entre outros direitos garantidos constitucionalmente ${ }^{1}$.

Segundo a OMS, diversos fatores podem colocar em risco a saúde mental dos indivíduos; entre eles, rápidas mudanças sociais, condições de trabalho estressantes, discriminação de gênero, exclusão social, estilo de vida não saudável, violência e violação dos direitos humanos.

A partir dessa visão, não se concebe o ser humano limitado ao dualismo mente-corpo, mas dentro de uma análise estrutural, que envolve a abordagem dos aspectos biológico, psíquico e social ${ }^{2}$. Nesse sentido, a promoção da saúde mental deve envolver ações que permitam às pessoas a adoção e manutenção de estilos de vida saudáveis.

1 A. C. Lopes, C. A. de S. Lima e L. de F. SAntoro, Eutanásia, Ortotanásia e Distanásia: aspectos médicos e jurídicos, São Paulo, Atheneu, 2011.

2 C. L. dos Santos, J. A. dos Santos e M. C. C. L. Santos, Dano Psíquico, São Paulo, Oliveira Mendes, 1998. 


\section{SAÚDE PÚBLICA E VIOLÊNCIA PSÍQUICA}

Ao relacionar diretamente a saúde ao bem-estar físico e mental das pessoas, em perfeita consonância com as diretrizes lançadas pela Organização Mundial da Saúde (OMS), abre-se o debate para a associação da violência como um problema de saúde pública, responsável pela geração de inúmeros e inquestionáveis agravos ${ }^{3}$.

A OMS define a violência como «o uso de força física ou poder, em ameaça ou na prática, contra si próprio, outra pessoa ou contra um grupo ou comunidade que resulte ou possa resultar em sofrimento, morte, dano psicológico, desenvolvimento prejudicado ou privação».

Observa-se, portanto, que o ato de violência extrapola a seara da violência física, de modo a abarcar os atos resultantes de relações de poder, dentre os quais se incluem as diversas formas de violência psíquica. Não é outra a conceituação das origens da violência psíquica, segundo o Relatório Mundial Sobre Violência e Saúde ${ }^{4}$ :

«... o conceito de "uso de força física ou poder" deve incluir negligência e todos os tipos de abuso físico, sexual e psicológico, bem como o suicídio e outros atos auto infligidos. Esta definição cobre uma ampla gama de resultados, incluindo injúria psicológica, privação e desenvolvimento precário. Ela reflete um crescente reconhecimento entre pesquisadores da necessidade de incluir a violência que não produza necessariamente sofrimento ou morte, mas que, apesar disso, impõe um peso substancial em indivíduos, famílias, comunidades e sistemas de saúde em todo o mundo. Muitas formas de violência contra mulheres, crianças e idosos, por exemplo, podem resultar em problemas físicos, psicológicos e sociais que não representam necessariamente ferimentos, incapacidade ou morte. Tais consequências podem ser imediatas ou latentes e durar por anos após o ato abusivo inicial. Assim, definir as consequências somente em termos de ferimento ou morte limita a compreensão total da violência em indivíduos, nas comunidades e na sociedade em geral» 5 .

3 C. L. dos Santos e F. Moran Faloppa, «Tutela da Saúde e Dano Psíquico», Revista de Direito de Medicina, núm. 3 (2019).

${ }^{4}$ Ibid.

5 Organização Mundial de Saúde, Relatório Mundial sobre Violência e Saúde, Genebra, 2002, fonte https://www.opas.org.br/wp-content/uploads/2015/09/relatorio-mundialviolencia-saude.pdf (acesso em 11 de maio de 2019). 
A Resolução WHA49.25, de $1996^{6}$, que declara a violência como um dos principais problemas de saúde pública, formulou solicitação à Organização Mundial da Saúde para o desenvolvimento de uma tipologia da violência. Nesse sentido, apresentou-se a divisão da violência em três grandes categorias, conforme as características do autor do ato de violência: Violência dirigida a si mesmo (auto infligida); Violência interpessoal e Violência coletiva.

Os danos psíquicos tem como pano de fundo a ocorrência da violência intrapessoal, interpessoal (sob a forma física, psicológica, patrimonial) e coletiva em face de uma vítima determinada ou determinável.

\section{CARACTERIZAÇÃO DO DANO PSÍQUICO}

A caracterização do dano ou prejuízo psíquico abrange a presença dos seguintes componentes: a) cognitivo, envolve as crenças e pensamentos; b) emocional ou afetivo, representado pelo tipo e intensidade da emoção relacionada ao comportamento $(v$. gr. raiva, tristeza); $c$ ) o comportamento relacionado com a ação; $d$ ) nexo causal entre o prejuízo sofrido e a interação com os demais componentes. Nesse contexto, dano psíquico é a atitude hostil ou negativa praticada através de uma ou mais pessoas em um grupo identificável. Os danos ou prejuízos psíquicos possuem um elemento cognitivo (um estereótipo) e podem influenciar comportamentos (sob a forma de discriminação) ${ }^{7}$.

Nós somos todos vítimas ou potenciais vítimas de danos psíquicos com base nos relacionamentos interpessoais que estabelecemos. Desse modo nosso relacionamento em um determinado grupo, por razões étnicas, religiosas, de gênero, origem, orientação sexual, cor, aparência, etc., podem ser causar ou agravar danos psíquicos preexistentes. Tal constatação não se aplica apenas a minorias que são oprimidas pela maioria. Os danos psíquicos são uma via de mão dupla: podem ir da minoria social para a maioria social e vice-versa ${ }^{8}$.

A origem da questão decorre do fato de que o ser humano não consegue evitar categorizar as pessoas de acordo com os grupos em que se inserem. O estereótipo é um passo além da categorização. O estereótipo é a

${ }^{6}$ bttps://www.who.int/violence_injury_prevention/resources/publications/en/WHA4925_ eng.pdf (acesso em 11 de maio de 2019). livre).

7 Nesse sentido, E. Aronson et al., Social Psychology, 9. a ed,, pp. 414-415 (tradução

${ }^{8}$ Ibid., p. 415. 
generalização de um grupo de pessoas em que as características que compartilham possuem virtualmente todos os membros do grupo. O estereótipo pode ser físico, mental, ou ocupacional. Trata-se de processo cognitivo e pode ser tanto positivo como negativo. Cuida-se de técnica que utilizamos para simplificar o mundo. Isto porque o mundo é muito complexo para que tenhamos reações diferentes em todos os contextos - nós maximizamos nosso tempo cognitivo e energia desenvolvendo comportamentos e atitudes sobre tópicos específicos. Existe uma base neurológica para a eficiência cognitiva do fenômeno da estereotipização; dada a nossa capacidade limitada de processar informação faz com que peguemos atalhos para entendermos as pessoas ${ }^{9}$.

Para a correta compreensão dos fatores que desencadeiam a ocorrência do dano psíquico devemos analisar não apenas do ponto de vista do ofensor, mas também do ponto de vista da vítima. Uma característica comum das vítimas do dano psíquico é a diminuição de suas auto estimas, internalização da visão da sociedade de um grupo como sendo inferior, sem atrativos ou incompetente.

O dano psíquico tem origem em muitas forças no mundo social. Alguns ocorrem no nível do grupo ou instituição, que exige a conformidade a regras na sociedade. Outros ocorrem ao nível individual, na maneira como o processo de informação ganha significado na observação dos eventos. Da mesma forma que as normas sociais mudam, algumas vezes com reflexos nas leis e nos costumes, da mesma forma ocorre com o fenômeno do dano psíquico. Por décadas o homem foi considerado chefe da sociedade conjugal, sendo que apenas em 2002 que o Código Civil reconheceu a igualdade de direitos e deveres entre homens e mulheres no casamento. Rotineiros eram os tratamentos de «histeria» de mulheres pelos seus maridos em razão de suposta inadequação social do comportamento feminino. A esse fenômeno pode-se denominar conformidade normativa.

Porém, o dano psíquico passível de responsabilização cível e criminal abarca o conceito de trauma em razão de uma conduta identificável, ainda que desmembrados em uma série de atos no curso do tempo. O trauma afeta nossa fisiologia, incluindo nossa capacidade de pensar de forma integrada e completa. Dessa forma, deve ser entendido nos aspectos psicológicos, emocionais, mentais e espirituais ${ }^{10}$.

\footnotetext{
${ }^{9}$ Ibid.

${ }^{10}$ Cfr. C. Yoder, Trauma Healing: when violence strikes and community security is threatened, New York, Good Books, 2005, p. 9.
} 
O dano psíquico difere do estresse do cotidiano diário em razão de sua intensidade e duração. Envolve desde a capacidade de lidar ou responder a ameaças, a sensação de perda do controle de sua vida, mudança no sentido da vida de uma pessoa ou grupo de pessoas em termos de significado e ordenação ${ }^{11}$. Portanto, ocorrem em um contexto social, com interações dinâmicas dos indivíduos na sociedade. As condições sociais e significativas de uma experiência individual geralmente atua como causa ou contribui para a ocorrência do dano psíquico.

Portanto, esse olhar para a vítima não pode ser subtraído quando se analisa, por exemplo, uma vítima de roubo com restrição de sua liberdade que não consegue mais sair na rua sem ficar muito assustada com qualquer movimentação estranha ao seu redor. Tampouco, pode-se negar a ocorrência de lesão corporal a pretexto de ausência de lesão a integridade física da vítima do evento criminoso, cujo trauma mudou toda a sua rotina diária e forma de direcionamento de sua vida emocional, social e laboral (art. 129 do Código Penal - «ofender a integridade corporal ou a saúde de outrem»).

O tratamento do fenômeno do crime deve contemplar um enfoque necessário da responsabilização e reparação do dano pelo ofensor, bem como abranger todos os aspectos de saúde e sociais envolvidos, devendo o Estado fornecer serviços adequados de assistência às vítimas de crimes. Trata-se de realidade multifaceta que comporta distintos enfoques e linhas de atuação. Nesse sentido, aponta Judah Oudshoorn et al.:

«A maior parte dos recursos financeiros e humanos da máquina da justiça é gasto com ofensores. Desde a polícia para as cortes e prisões, a América do Norte gasta bilhões de dólares naqueles que causaram o dano criminal. Isso é muitas vezes à custa de satisfazer as necessidades das vítimas» ${ }^{12}$.

\section{DANO PSÍQUICO E VIOLÊNCIA CONTRA MULHERES}

De acordo com estudo realizado pela $\mathrm{ONU}$, a violência de gênero é o crime com menor índice de denúncias, pois apenas em 10 por 100 dos casos são levados ao conhecimento da autoridade policial. A subnotificação dessa modalidade delitiva e a ausência de estratégias adequadas para

${ }^{11}$ Ibid., p. 10.

12 J. OudSHOORn et al., The Little Book Of Restorative Justice For Sexual Abuse, New York, Good Books, 2015, p. 3. 
o combate a sua prática nos leva à constatação de que a cada 15 segundos uma mulher é agredida ${ }^{13}$.

Ao escolher reportar o fato a autoridade policial a mulher é desempoderada da solução do problema, uma vez que a «verdade dos fatos» terá que ser percorrida a fim de que se possa imputar a alguém o estigma de culpado.

É na seara da culpabilidade que a violência contra a mulher encontra a maior dificuldade de controle estatal. A culpabilização da mulher pelos delitos que sofre impede ou dificulta a responsabilização do agressor, além de ser ato atentatório a sua dignidade, pode gerar ciclos contínuos de revitimização ${ }^{14}$. Há muito que se percorrer para que o ofensor, a sociedade e o próprio Poder Judiciário tenham consciência da real consciência da ilicitude do fato diante das mais variadas formas de violência que predominam em nossa sociedade: física, psíquica e coletiva. A esse respeito pondera Maria Berenice Dias:

«Estudos tem sido feitos para chamar a atenção aos prejuízos físicos e psicológicos decorrentes dos maus-tratos. O transtorno do estresse póstraumático — sinalizado pela depressão, ansiedade, inaptidão global à vida cotidiana, alterações psicossomáticas - retrata as alterações mais frequentes. Esses danos podem ser mensurados, mas para isso é indispensável que sejam visualizados. Somente quando a sociedade adquirir consciência das consequências devastadoras dos delitos contra a mulher é que se poderá vislumbrar a possibilidade de reversão dessa realidade cruel (...)».

«Urge a adoção de uma política mais assistencial e reparadora às vitimas que conseguem vencer a barreira do pavor e da submissão. Igualmente resta evidenciado que a avaliação psicológica é uma ferramenta indispensável para o reconhecimento do fato delituoso. De outro lado, o acompanhamento psicológico das vitimas permite minimizar as nefastas sequelas decorrentes da prática de delitos que o Estado negligencia em prevenir e não consegue controlar» ${ }^{15}$.

${ }_{13}$ M. B. Dias, «Prefácio», em S. L. R. Rovinski, Dano Psíquico Em Mulheres Vitimas de Violência, Rio de Janeiro, Lumen, 2004, p. XV.

${ }_{14}$ A esse respeito, pondera RovinSKI, em ibid., p. XIX: «... a própria denúncia se reveste de um estigma que, ao invés de libertar a mulher, termina por oprimi-la através de uma culpa da qual não tem responsabilidade». E prossegue a fls. XX/XXI: «... quando realizam sua denúncia defrontam-se com estruturas sociais e institucionais despreparadas para recebê-las (...) a impotência das instituições para dar uma solução ao problema desqualifica o sofrimento relatado e há uma tentativa de responsabilizar a própria vitima pelos fatos que está vivenciando».

${ }^{15}$ Ibid., pp. XV/XVI. 
A ausência de enfrentamento adequado do problema nos conduz à perpetuação das desigualdades em nossa sociedade, pois possui reflexos no esfera laboral por meio dos fenômenos da segregação horizontal (acesso ao trabalho) e segregação vertical (acesso a cargos de chefia e liderança), política (igualdade de homens e mulheres na representatividade perante os órgãos legiferantes, executivos e judiciários).

A violência contra a mulher pode ser definida como:

«qualquer ato de violência que tem por base o gênero e que resulta ou pode resultar em qualquer em dano ou sofrimento de natureza física, sexual, psicológica, inclusive ameaças, a coerção ou a privação arbitrária da liberdade, que se produza na vida pública ou privada» ${ }^{16}$.

Pode-se mencionar como exemplos as críticas, humilhações, ameaças, código de condutas a serem adotadas na vida pública e privada, tais como vestimenta e comportamentos ditos «adequados». A violência, seja de que tipo for, é compreendida como resultante de uma interligação de fatores individuais, de relacionamentos sociais, culturais e ambientais» ${ }^{17}$.

A principal tarefa estatal no acolhimento dessas vítimas é propiciar que vivenciem a própria história integrando o dano psíquico sofrido como parte dela, o que propicia que estas passem do status de vítimas para a de sobreviventes, rompendo-se os ciclos vitimizatórios subsequentes ao fato danoso. A esse respeito pondera Oudshoorn que o termo vítima:

«... indica que algo prejudicial e incontrolável foi feito a alguém e que o incontrolável foi feito a alguém sem o seu consentimento. Usar «vítimas» nos permite dizer que o que aconteceu com esses indivíduos não foi escolhido, nem culpa deles. Foi imposto: uma violação. No entanto, uma precaução com este termo é que as vítimas não permanecem necessariamente indefesas ou permanentemente aprisionadas em sua condição de vítima. Muitas vezes, outros querem dizer às vítimas como responder, o que não ajuda. No entanto, quando as escolhas ou processos de resiliência são disponibilizados para as vítimas, eles são mais capazes de tomar medidas para a cura» ${ }^{18}$.

${ }^{16}$ Declaração e Plataforma de Ação da IV Conferência Mundial Sobre a Mulher. Pequim, 1995, disponível em bttp://unfpa.org.br/Arquivos/declaracao_beijing.pdf, acesso em 17 de maio de 2019.

17 S. L. R. Rovinski, Dano Psíquico Em Mulheres..., op. cit., p. 7.

18 J. Oudshoorn et al., The Little Book Of Restorative..., op. cit., pp. 12-13. 


\section{DANO PSÍQUICO E VIOLÊNCIA CONTRA IDOSOS}

De acordo com o Disque Direitos Humanos ou Disque 100, Programa da SPDCA/SDH em 2017 foram registradas 32.632 denúncias de violência contra idosos. Os tipos de denúncia se dividem em (podendo haver mais de um tipo de violência por denúncia): negligência (77 por 100), violência psicológica (51 por 100); abuso financeiro ou violência patrimonial (38 por 100), violência física e maus tratos (26 por 100).

O especial grau de vulnerabilidade em que os idosos se encontram torna-os mais suscetíveis a violências psicológicas e maus tratos, até porque é o setor mais carente em nossa sociedade de uma política pública de proteção à saúde e assistência social, além de ser o primeiro elo da unidade familiar que é fragilizado.

A criação e fortalecimento de redes de proteção de idosos é não somente recomendável, mas absolutamente necessário, especialmente considerando o fato de que o Brasil está vivenciando fenômeno de envelhecimento de sua população ante o aumento da expectativa de vida.

Por conseguinte, a fragilização e dependência dos idosos constitui importante fator na caracterização de danos psíquicos, razão pela qual inclusive é considerada agravante genérica no Código Penal e possui crimes específicos estabelecidos no Estatuto do Idoso (Lei n. 10.741/2003).

\section{DANO PSÍQUICO E VIOLÊNCIA CONTRA CRIANÇAS}

As crianças constituem grupo de especial vulnerabilidade em nossa sociedade, pois se reveste de muitos rostos e formas: abuso físico, abuso sexual, negligência, abuso emocional, dentre outros.

As estatísticas são assustadoras. A cada cinco minutos uma criança morre de violência ${ }^{19}$; cerca de um bilhão de crianças — mais da metade de todas as crianças de dois a dezessete anos- tenha sofrido violência emocional, física e/ou sexual ${ }^{20}$; uma em cada dez meninas - 120 milhões - com menos de vinte anos de idade foi submetida a atos sexuais forçados ${ }^{21}$; pra-

19 Parceria Global para Acabar com a Violência Contra Crianças, 2016.

20 WHO, 2016.

${ }^{21}$ UNICEF, 2014. 
ticamente uma em cada dez crianças 250 milhões em todo o mundo — vive em um país afetado por conflitos- ${ }^{22}$.

A violência pode causar danos psíquicos irremediáveis para a saúde física, psicológica e mental de uma criança. Sem apoio e cuidados adequados, a violência e o trauma podem ter efeitos a longo prazo no desenvolvimento da criança e na vida futura.

Da mesma forma, as crianças que sofreram violência também são mais propensas a perpetuar o círculo de violência, transmitindo padrões de violência aos seus pares ou às futuras gerações.

Portanto, urge a conscientização da violência contra crianças em nossa sociedade, para que tenhamos adultos saudáveis, comunidades e sociedades saudáveis.

\section{CONCLUSÃO}

A saúde é um estado de completo bem estar físico, psíquico e social e não apenas a ausência de doença. A sociedade, o Estado e os indivíduos devem se preocupar com a saúde não apenas em sua dimensão individual, mas sobretudo coletiva. Portanto, os estereótipos e discriminações correlacionadas devem ser continuamente revistos em nossa sociedade, possibilitando-se alcançar maior grau civilizatório tanto maior for a igualdade efetiva de seres humanos em nossa sociedade.

O dano psíquico é patologia que pode decorrer de um ou mais eventos traumáticos. A passagem do status de vítima para o de sobrevivente constitui importante degrau a ser alcançado para que preservação de sua dignidade humana.

O dano psíquico, qualquer que seja a sua origem é ato ilícito passível de indenização e responsabilização criminal.

\section{BIBLIOGRAFÍA}

Aronson, E., et al.: Social Psychology, 9. a ed., Pearson, 2016.

Lopes, A. C.; Lima, A. C. A. de S., e SANTORO, L. de F.: Eutanásia, ortotanásia e distanásia: aspectos médicos e jurídicos, 1. ${ }^{a}$ ed., São Paulo, Atheneu, 2011.

Organização Mundial da Saúde: Constituição da Organização Mundial da Saúde (OMS/WHO). ONU. Declaração e Plataforma de Ação da IV Conferência Mun-

${ }^{22}$ UNICEF, 2016. 
dial Sobre a Mulher, Pequim, 1995, disponível em bttp://unfpa.org.br/Arquivos/declaracao_beijing.pdf (acesso em 17 de maio de 2019).

Oudshoorn, J., et. al.: The Little Book Of Restorative Justice For Sexual Abuse, New York, Good Books, 2015, p. 3.

Santos, C. L. dos; Santos, J. A. dos, e Santos, M. C. C. L.: Dano Psíquico, São Paulo, Oliveira Mendes, 1998.

Rovinski, S. L. R.: Dano Psíquico Em Mulheres Vitimas de Violência, São Paulo, Lumen Juris, 2004.

YODER, C.: Trauma Healing: when violence strikes and community security is threatened, New York, Good Books, 2005. 